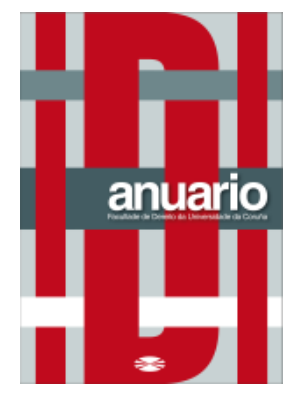

Anuario da Facultade de Dereito da Universidade da Coruña

Vol. 22 (2018), pp. 463-470

ISSNe: 2530-6324 || ISSN: 1138-039X

DOI: https://doi.org/10.17979/afdudc.2018.22.0.5197

\title{
A USUCAPIÓN POLO ESTADO ESPAÑOL DO MUSEO CERRALBO, LOGO DE SER INTERVIDO $M A N U$ MILITARINA POSGUERRA CIVIL, A PROPÓSITO DA SENTENZA DA AUDIENCIA PROVINCIAL DE MADRID, DO 18 DE DECEMBRO DE 2007
}

\author{
ERNESTO VÁZQUEZ-REY \\ Investigador predoutoral na Área de Dereito Administrativo \\ Universidade da Coruña \\ ÁNGEL ARCAY BARRAL \\ Historiador e mestrado en Historia e Patrimonio, con especialidade en Arquivos Históricos
}

Resumo: O presente comentario versa sobre unha sentenza da Audiencia Provincial de Madrid, ditada o 18 de decembro de 2007, na que se resolve un recurso de apelación sobre a propiedade da metade indivisa do Palacio do XVII marqués de Cerralbo, Enrique de Aguilera e Gamboa, que resultou ter adquirido o Estado español por usucapión, aínda que a posesión fora obtida manu militari na posguerra civil española.

Palabras clave: memoria histórica, patrimonio cultural, museo Cerralbo, usucapión, prescripción adquisitiva.

Abstract: This comment analyzes the sentence of the Provincial Court of Madrid, passed in December 18, 2007. In this appeal, on the ownership of the undivided half of the Palace of the XVII Marquis of Cerralbo, Enrique de Aguilera and Gamboa, is resolved. This building was acquired by the Spanish State through usucaption, although the possession was obtained manu militari after the Spanish Civil War.

Keywords: historical memory, cultural heritage, Cerralbo museum, usucaption, acquisitive prescription. 
1. Na sentenza da Sección 25a , do Civil, da Audiencia Provincial de Madrid, que 1

se vai tratar, do 18 de decembro de 2007, no procedemento número 579/2007, procede analizar a declaración de dominio a favor do Estado, por prescripción adquisitiva extraordinaria, do Palacio do marqués de Cerralbo, que fora intervido manu militari pola Administración central na posguerra civil española. Para unha mellor comprensión da problemática formulada, demasiado extensa e complexa, é preciso realizar unha síntese do marco sobre o que se vai tomar a decisión que -en adianto- será negativa á declaración de dominio da metade indivisa do Palacio do marqués de Cerralbo a favor da súa comunidade hereditaria. Os elementos históricos -previos ao proceso xudicial- a ter en conta son: (a) En 1882 os irmáns Antonio e Amelia del Valle Serrano, sucesivos marqueses de Villa Huerta, comezan a edificar un Palacio entre as rúas madrileñas de Ventura Rodríguez, Ferraz e Juan Álvarez de Mendizábal, xunto co seu padrasto, o XVII marqués de Cerralbo. A obra remata en 1894, cun Palacio composto de semisoto, entresollado, piso principal e sobrado, ademáis da portaría e grande escaleira; (b) Antonio del Valle Serrano, I marqués de Villa Huerta, falece no ano de 1900, sendo a súa herdeira a referida irmá, Amelia del Valle Serrano; (c) o XVII marqués de Cerralbo, Enrique de Aguilera e Gamboa, adquire da súa fillastra, Amelia del Valle Serrano, II marquesa de Villa Huerta, a metade indivisa do referido Palacio, substanciada na grande escaleira, portaría, piso principal e sobrado, por compravenda realizada o 8 de xullo de 1922, perante o Notario de Madrid, Luís Gallinal e Pedregal; (d) o XVII marqués de Cerralbo constrúe ás súas expensas un piso terceiro, por detrás dos torreóns do sobrado, e -ao tempo- este e a súa fillastra, a II marquesa de Villa Huerta, instalan as súas valiosísimas coleccións de arte no piso principal, portaría e grande escaleira do Palacio; (e) o dito XVII marqués de Cerralbo, falece o 27 de agosto de 1922, tendo outorgado testamento o 30 de xuño dese ano, perante o antedito Notario. Esta disposición é ampliada cun codicilo, outorgado o 17 de agosto de 1922 perante o mesmo fedatario; (f) o Estado, en cumprimento das disposicións testamentarias do referido XVII marqués de Cerralbo acepta o legado das coleccións de obras de arte dispostas no Palacio, sen que nel se inclúa ningún dereito de propiedade sobre o inmoble, mediante Real Orde do 10 de abril de 1924, clasificándose o Museo Cerralbo como unha Fundación benéficodocente, mediante Real Orde do 24 de setembro de 1924; (g) Amelia del Valle Serrano, II marquesa de Villa Huerta, falece o 7 de xaneiro de 1927, extinguíndose o usufruto sobre a metade indivisa do Palacio que viña ostentando dende o falecemento do seu padrasto. Ao tempo, a súa metade indivisa sobre o Palacio é legada á Asociación Católica de la Santísima Trinidad y María Inmaculada para a instalación dun asilo residencial para estudantes; (h) por escritura pública do 12 de maio de 1934, o representante legal da testamentaría de Enrique de Aguilera e Gamboa entrega ao Padroado da Fundación Cerralbo tódolos bens, obxectos e valores pertencentes á Fundación, en cumprimento da Orde do 22 de marzo de 1934, pero sen incluir a metade

http://www.poderjudicial.es/search/openDocument/06cf55dafd5e8928/20080313 
indivisa do referido Palacio; (i) en 1939 é destituído do cargo de director do Museo Cerralbo, Juan Cabré Agulló, acusado de colaboracionista co goberno da II República española, malia a súa designación vitalicia polo testamento do XVII marqués de Cerralbo; (j) por Orde do 21 de abril de 1942, do ministro de Educación Nacional da Ditadura franquista, José Ibáñez Martín, o Museo Cerralbo adscríbese ao Corpo Facultativo de Arquiveiros, Bibliotecarios e Arqueólogos, desígnándose á súa sobriña, Consuelo Sanz-Pastor e Fernández de Piérola, como directora; (k) o único testamenteiro supervivente do XVII marqués de Cerralbo, Antonio Becerril Lagarda, maxistrado do Tribunal Supremo, confecciona o caderno particional da herdanza do marqués, cuxa protocolización ten lugar logo do seu pasamento, en 1943, cunha adición da comunidade hereditaria, expresando a súa disconformidade coa atribución polo testamenteiro das plantas segunda e terceira a favor do Estado; (l) o Estado, por escritura pública do 31 de decembro de 1944, compra á Asociación Católica de la Santísima Trinidad y María Inmaculada a outra metade indivisa do Palacio do XVII marqués de Cerralbo, que lle pertencía por legado testamentario de Amelia del Valle Serrano, II marquesa de Villa Huerta; (m) a comunidade hereditaria de Enrique de Aguilera e Gamboa outorga unha escritura de adición ao caderno particional, o 28 de xaneiro de 1952, na que se adxudican os pisos segundo e terceiro do Palacio; (n) nunha acta do Padroado da Fundación Museo Cerralbo, do 30 de novembro de 1954, recóllese, na relación de bens inmobles que o XVII marqués legou á "Nación española", a metade indivisa do Palacio descrito supra; (ñ) en 1962, a directora do Museo Cerralbo, Consuelo Sanz-Pastor, dirixe unhas obras de consolidación no Palacio. Neste momento son descerrallados os pisos segundo e terceiro do inmoble, onde se depositaban os arquivos nobiliarios da comunidade hereditaria do XVII marqués de Cerralbo e se celebraban as Xuntas de Herdeiros, que pasan a ser ocupados manu militari pola referida Dirección, e en cuxas obras foi derruído o piso terceiro; todo o cal se ve reflectido nas actas de requirimento que outorga a comunidade hereditaria nos meses de xaneiro, febreiro e marzo de 1962, a presenza do Notario de Madrid, Eduardo López Palop.

2. A seguir de todo o anterior deu inicio o proceso xudicial que nos ocupa, e que se substancia nos seguintes antecedentes de feito: (a) na década de 1980, a Administración do Estado promove un expediente de dominio, tramitado polo Xulgado de $1^{\text {a }}$ Instancia, núm. 10, de Madrid, co número de procedemento 971/89, no ánimo de reanudar o tracto rexistral sucesivo da metade indivisa do Palacio de referencia, inscrito a favor do XVII marqués de Cerralbo, Enrique de Aguilera e Gamboa; (b) o 26 de xullo de 1995 dítase auto polo que se declara xustificada a reanudación do tracto rexistral sucesivo a favor do Estado da metade indivisa do Palacio de Cerralbo, ao terse cumprido o prazo da prescripción adquisitiva sobre o mesmo; (c) contra o auto anterior, varios membros da comunidade hereditaria interpoñen recurso de apelación, que se estima, revogándose na súa integridade, por un novo auto do 4 de novembro de 1997, co número de recurso 337/1996, ditado pola Sección $11^{\text {a }}$ da Audiencia Provincial de 
Madrid ; (d) a Avogacía do Estado interpón, o 23 de xullo de 1999, demanda de xuízo de maior contía na que reclama a declaración de dominio da metade indivisa do Palacio de Cerralbo, que lle corresponde por herdanza do XVII marqués de Cerralbo ou, subsidiariamente, por prescripción adquisitiva ordinaria, ou, subsidiariamente, extraordinaria; (e) a devandita demanda é admitida a trámite, por providencia ditada o 27 de xullo de 1999, ordeando o emprazamento de todas as persoas demandadas, para a 3 súa personación ; (f) o día 26 de xullo de 2001 preséntase, pola comunidade hereditaria demandada, o escrito de contestación á demanda e -implícitamente- demanda reconvencional, solicitando que se declare que a parte adquirida polo XVII marqués de Cerralbo -á súa fillastra- é propiedade da comunidade hereditaria deste, diferenciándose en que a propiedade dos pisos segundo e terceiro é plena, mentres que a que lles corresponde sobre o resto do Palacio é nuda propiedade. Alternativamente, que a propiedade dos pisos segundo e terceiro corresponde á comunidade hereditaria do XVII marqués de Cerralbo, sendo o resto da súa adquisición -isto é: portaría, grande escaleira e piso principal- propiedade do Estado, en tanto que titular do Museo Cerralbo. En terceiro lugar, que o Estado non gañou por usucapión ningunha das partes que ocupa o Museo; ademáis da expresa imposición en custas e a práctica das inscricións rexistrais oportunas; (g) tendo dado traslado á parte actora, a Avogacía do Estado presenta escrito de contestación á reconvención, o 29 de xaneiro de 2002, insistindo na constatación posesoria do Estado sobre a metade indivisa do Palacio, mediante as actas do Padroado da Fundación Museo Cerralbo, o caderno particional da herdanza do XVII marqués de Cerralbo e as manifestacións efectuadas no testamento de Amelia del Valle Serrano, II marquesa de Villa Huerta; (h) o 4 de febreiro do 2002 exténdese dilixencia de ordenación, pola que se ten por evacuada pola Avogacía do Estado a réplica, dándose traslado desta á representación da parte demandada para súa dúplica; (i) a parte demandada recorre a dilixencia, a Avogacía do Estado impugna o recurso e este é desestimado por auto do 15 de abril de 2002; (j) logo do anterior tramítase un incidente de recusación da anterior maxistrada-xuíza titular do Xulgado de $1^{\text {a }}$ Instancia, núm. 63, de Madrid, Miriam Iglesias García, desestimada por auto do 27 de maio de 2003; (k) a mesma parte presenta, o 30 de maio de 2002, escrito de dúplica no que se insiste no uso

2

http://www.poderjudicial.es/search/openDocument/326890577dc80a13/20031128

Neste momento procesual a comunidade hereditaria personada fórmase polos seguintes herdeiros: Juan Francisco de Asís e Esperanza Martín de Aguilera e Arenales; Concepción Simón; Esperanza Febrel de Aguilera; Pilar, Rosario, Francisco e Jaime Febrel Simón; Íñigo Febrel Melgarejo; Gonzalo, José $\mathbf{M}^{\mathrm{a}}, \mathbf{M}^{\mathrm{a}}$ Francisca, Jaime, Dolores, César, Enrique, J. Fernando e Esperanza Villalonga Martín de Aguilera; Agustín Barbero de Aguilera; Margarita, Fernando $\mathbf{M}^{\mathrm{a}}$ e $\mathbf{M}^{\mathrm{a}}$ Teresa de Aguilera Narváez; Isabel e $\mathbf{M}^{\mathrm{a}}$ Francisca Martín Bellefroid; $M^{a}$ Isabel Loring García; Asunción, Enrique e $\mathbf{M}^{\mathrm{a}}$ Teresa Espinosa de los Monteros Martín; José $\mathbf{M}^{\mathrm{a}}$ Villalonga; Gonzalo e $\mathbf{M}^{\mathrm{a}}$ Teresa Martín de Aguilera Vigo; Estela del Amo Fernández; Alfonso e Guía del Mar Martín de Aguilera del Amo; Mireya e Javier Martín de Aguilera Sastre; Ma Ángeles Núñez Ispa; Marianela de Aguilera Lodeiro e Nuria de Aguilera Núñez.

Asimesmo, a comunidade hereditaria en situación de rebeldía procesual fórmase polos seguintes herdeiros: Isabel de Aguilera Sánchez; $M^{a}$ Elena Melgarejo Rojo; Leticia, Esperanza, José e Fernando Febrel Melgarejo; Santiago de Aguilera Narváez; Fátima e Juan Espinosa de los Monteros Martín; José Luís del Campo Mora; Pilar de Aguilera Narváez; Águeda Villalonga Martín de Aguilera; Jaime e Carlos Martín de Aguilera del Amo e Eulalia e Pilar Urcola Fernández. 
pola testamentaría do XVII marqués de Cerralbo, e a súa comunidade hereditaria, dos pisos segundo e terceiro do referido Palacio e expón que na súa reconvención está a exercitar unha acción declarativa de dominio; (1) por auto do 3 de xuño de 2002 tívose por evacuado o trámite de dúplica e ordeóuse o recibimento do preito a proba, abríndose o primeiro período para a súa proposición. A parte actora -e reconvida- propón proba documental, testemuños de particulares do expediente de dominio -referido supra-, declaración das testemuñas Lourdes Vaquero Argüelles e Pilar Calzas Cintero, e recoñecemento xudicial do inmoble. Pola súa banda, a parte demandada -e reconvintepropón proba documental, documentación a obter por oficios dirixidos ao Archivo General de Protocolos del Ilustre Colegio Notarial de Madrid, ao Ministerio de Educación y Cultura, ao Ayuntamiento de Madrid, ao Archivo General de la Administración Española e ao Colegio de Arquitectos de Madrid, e por mandamento ao Rexistro da Propiedade, núm. 25, de Madrid; recoñecemento xudicial do inmoble, así como proba pericial e declaración das testemuñas Antonio Gómez Hernández, Antonio Juberías Garbajosa, Juan Morán Cabré e Fernando Chueca Goitia, renunciando logo ás testemuñas segunda e terceira. Practicáronse todas as probas propostas, agás o recoñecemento xudicial do inmoble e un punto do ditame pericial, solicitado pola parte demandada; (m) logo de practicada a proba e ao non ter accedido o tribunal á celebración de vista, a parte actora presenta o seu escrito de conclusións, o 30 de xuño de 2005. Do mesmo xeito, a parte demandada fai o propio, o 21 de febreiro de 2006, corrixindo algunhas omisións e grallas por outro escrito presentado o 1 de marzo de 2006; (n) o mesmo día, a xuíza substituta do Xulgado instrutor, dita providencia pola que acorda ter por presentado o escrito de conclusións da parte demandada, e requírea para que achegue ás actuacións todos os documentos aparecidos logo do falecemento de Abilio Barbero de Aguilera; (ñ) a citada providencia é recorrida pola Avogacía do Estado en reposición, sendo o recurso impugnado de contrario e resolvéndose por auto do 9 de maio de 2006, desestimando a orde de unión ás actuacións do escrito de conclusións da parte demandada, e estimando o recurso en canto ordenaba requirir á mesma parte para a aportación de documentos, resolvendo o seu desglose e devolución. Na mesma resolución declaráronse concluídos os autos, mandando traelos á vista con citación das partes para sentenza, cuxa firmeza se declarou por dilixencia de ordenación, extendida o 13 de xuño de 2006; (o) a maxistrada-xuíza titular do Xulgado de Primeira Instancia, núm 63, de Madrid, Lourdes Menéndez González-Palenzuela, dita a sentenza, núm. 165/2006, en primeira instancia, o 1 de setembro de 2006, no procedemento de maior contía número 512/99, estimando parcialmente a demanda da Avogacía do Estado e declarando que a Administración central é propietaria do piso principal, grande escaleira e portaría do Palacio do XVII marqués de Cerralbo. Do mesmo xeito, sobre a demanda reconvencional presentada pola comunidade hereditaria do referido marqués, estima a súa pretensión alternativa e declara que lle corresponde a propiedade dos pisos segundo e terceiro do mesmo Palacio, entrando o resto da metade indivisa do inmoble, adquirido polo XVII marqués de Cerralbo á súa fillastra, Amelia del Valle Serrano, a formar parte do legado que constitúe o Museo Cerralbo; e (p) a Avogacía do Estado presenta recurso de apelación contra a anterior sentenza, no que solicita que se declare que a metade indivisa do Palacio de Cerralbo corresponde na súa integridade ao Estado, 
por legado do XVII marqués de Cerralbo, ou, subsidiariamente, por prescripción adquisitiva ordinaria, ou, subsidiariamente, por prescripción adquisitiva extraordinaria; contra o que a representación procesual da parte demandada formula oposición, solicitando que se rexeite o recurso de apelación e se confirme a sentenza recorrida.

Cabe salientar que unha parte da comunidade hereditaria do XVII marqués de Cerralbo -indicada supra- continúa en situación procesual de rebeldía, sen deducir oposición, nin efectuar alegación ou manifestación algunha, fronte ao recurso de apelación promovido de adverso.

3. A sentenza comeza aceptando os fundamentos de dereito da resolución apelada, en canto non contradigan os da alzada; polo que, limitado o recurso á determinación da propiedade dos pisos segundo e terceiro -hoxe derruído- do Palacio de Cerralbo, na que foi concretada a metade indivisa do propio inmoble, inscrito a nome de Enrique de Aguilera e Gamboa, XVII marqués de Cerralbo, a cuestión litixiosa queda circunscrita á interpretación da vontade testamentaria do referido marqués e á determinación da concorrencia, ou non, dos requisitos da prescripción adquisitiva a favor do Estado.

En canto á primeira cuestión, é competencia da xulgadora de instancia interpretar o testamento de Enrique de Aguilera e Gamboa, prevalecendo o seu criterio, ao non entendérense as conclusións contidas na sentenza apelada como arbitrarias, ilóxicas, absurdas, irracionais, ou contrarias ao contido da disposición testamentaria referida ou á efectiva vontade do testador . Neste sentido, mantívose esta interpretación pola Audiencia Provincial, segundo a cal non se incluíu a propiedade do Palacio obxecto de litixio- no legado realizado a favor da "Nación española", polo que só podería sustentarse a titularidade dominical pretendida polo Estado sobre os pisos segundo e terceiro do inmoble na prescripción adquisitiva extraordinaria, ao non terse xustificado a concorrencia do xusto título, requirido para a usucapión . No que respecta á concorrencia, ou non, dos requisitos para a prescripción adquisitiva a favor do Estado, resulta acreditado que este veu posuíndo todo o inmoble en concepto de dono, de xeito público e ininterrompido durante máis de trinta anos -dende mediados de 1962 ata o 26 6

de xuño de 2001- · Por conseguinte, a cuestión litixiosa queda reducida a examinar a concorrencia do requisito da pacificidade da posesión detentada polo Estado dende

\footnotetext{
4

Como ten reiterado a Sala Primeira do Tribunal Supremo -entre outras- nas sentenzas do 7 de decembro de 1979, do 8 de febreiro de 1980, do 1 de xullo de 1985, do 11 de decembro de 1992 ou do 9 de outubro de 2003 .

Como precisa a sentenza da Sala Primeira do Tribunal Supremo, do 5 de maio de 2005, referíndose ao dereito de propiedade: "[...] porque por título apto para la usucapión ha de entenderse el acto que legalmente bastaría para, acompañado de la tradición, transmitir el derecho". 6

Non consta no proceso que a prescripción adquisitiva se teña interrompido, ben por calquera recoñecemento expreso ou tácito, como prescribe o art. 1948 CC, ou mediante a interrupción da posesión, naturalmente -ao abeiro do disposto no art. 1944 CC-, ou civilmente -con base nos arts. 1945 a 1947 CC-.
} 
1962. Aquí debemos separar entre posesión violenta e posesión non violenta, e posesión pacífica e posesión non pacífica, xa que toda posesión violenta é non pacífica e toda posesión pacífica é non violenta. Non obstante, o carácter violento é un vicio xenérico que afecta á posesión en si mesma e o carácter pacífico é un requisito adicional da posesión, hábil para a usucapión, polo que pode unha posesión non ser pacífica sen que medie violencia, necesariamente. Por isto, no caso que analizamos, a iniciación da posesión polo Estado en 1962 non pode cualificarse de violenta, porque non se revelou o emprego de forza irresistíbel, coacción, intimidación ou ameaza sobre os herdeiros do XVII marqués de Cerralbo -posuidores da parte litixiosa do inmoble- para a ocupación das dependencias sinaladas supra. Por este motivo, situando o inicio da posesión ad usucapionem do Estado principiando o ano de 1964 -máis dun ano despois do acto de ocupación posesoria-, na data do 23 de xullo de 1999 -momento de interposición da demanda- o Estado tiña posuído o Palacio de Cerralbo en concepto de dono, pública, pacífica e ininterrompidamente por un período superior aos trinta anos, establecidos no artigo 1959 do Código Civil, e así, teríase consumado ao seu favor a prescripción adquisitiva do dominio sobre as dependencias obxecto de litixio, polo que a comunidade hereditaria do XVII marqués de Cerralbo viu truncada a súa pretensión.

4. A sentenza aquí analizada resolve un extenso preito sobre a usucapión da metade indivisa do Palacio de Cerralbo, ocupado manu militari polo Estado na posguerra civil española, admitindo que existíu unha actuación administrativa que debeu ser cuestionada e impugnada nese momento pola comunidade hereditaria do XVII marqués de Cerralbo, e indicando que, en calquera forma, aínda que se considerara que a ocupación pola Administración das dependencias obxecto de litixio constituíron un acto violento -ao romper as pechaduras instaladas polo secretario da testamentaría do referido XVII marqués- concluiríase igualmente na prescripción adquisitiva do dominio a favor do Estado. A maior abundamento cítase o fundamento de dereito segundo da sentenza da Sala Primeira do Tribunal Supremo, do 25 de xaneiro de 2007, que literalmente di que "[...] ni es imaginable pensar que las trágicas circunstancias de una guerra civil y su postguerra hagan violenta o por la fuerza una posesión contra la que no se reclamó por el demandante hasta el año 1997 [...]", invisibilizando a dramática situación de espolio sufrido polas persoas que foron acusadas de republicanas, ou de colaboracionistas co lexítimo réxime constitucional da II República española, e o clima de submisión social instaurado no Estado español dende o alzamento militar de 1936 ata despois do pasamento do ditador Franco -en 1975- e a instauración do novo réxime político de Monarquía parlamentaria, en 1978. Neste sentido, cabe sinalar a destitución de Juan Cabré Agullo como director do Museo Cerralbo. Este, aínda sendo designado con carácter vitalicio polo fundador da institución museística, foi apartado do seu cargo en 1939, logo da aprobación da Lei do 9 de febreiro, de responsabilidades políticas; ao noso xuízo, nunha aplicación sui

"La posesión ha de ser en concepto de dueño, pública, pacífica y no interrumpida.", como se recolle no art. $1941 \mathrm{CC}$. 
generis do artigo 4.d) da citada norma. Por outra banda, a sentenza obxecto de comentario afianza a lexitimación dos botíns de guerra, xa que a ocupación do Palacio do marqués de Cerralbo pola Administración do Estado pode considerarse como unha incautación encuberta, ao non haber proceso instruído contra as persoas integrantes da comunidade hereditaria de Enrique de Aguilera e Gamboa, ao abeiro do disposto na Lei do 19 de febreiro de 1942, sobre reforma da Lei de responsabilidades políticas. A modo de peche, cabe concluír na necesidade de que dende os poderes lexislativo e executivo do Estado español se formulen -respectivamente- proposicións ou proxectos de lei que traten a forma de investigar e revertir os espolios patrimoniais cometidos no período antes sinalado, e que deixaron a centos de familias en situación de desamparo xurídico, aínda cando o Estado español pasou -formalmente- dunha Ditadura a un sistema democrático. cada confianza por nombramiento del Gobierno del Frente Popular, con retribución o sin ella, salvo los que deban su nombramiento a la elección y fueran de filiación política completamente hostil al mismo. También se considerarán comprendidos en este caso los que, sin nombramiento de dicho Gobierno, hubieren continuado desempeñando con él cargos de aquella índole en la Administración Central." 